\title{
Downregulation of CYP1A2, CYP2B6, and CYP3A4 in Human Hepatocytes by Prolyl Hydroxylase Domain 2 Inhibitors via Hypoxia-Inducible Factor- $\alpha$ Stabilization ${ }^{\circledR}$
}

\author{
Hiroki Takano, Jun-ichi Yamaguchi, Sota Kato, @Makoto Hamada, @Mika Tada, and Hiromi Endo \\ Drug Safety and Pharmacokinetics Laboratories (H.T., J.Y., M.T., H.E.), Pharmacology Laboratories (S.K.), and Chemistry \\ Laboratories (M.H.), Taisho Pharmaceutical Co., Ltd., Saitama, Japan
}

Received May 19, 2020; accepted October 2, 2020

\begin{abstract}
Hypoxia-inducible factor (HIF) is associated with the expression of CYP, but the underlying mechanism remains uncertain. In this study, we investigated the effect of HIF- $\alpha$ stabilization caused by novel prolyl hydroxylase domain (PHD) 2 inhibitors, which are HIF- $\alpha$ stabilizers that mimic hypoxia, on the expressions of CYP1A2, CYP2B6, and CYP3A4 in human hepatocytes. An mRNA expression analysis of human hepatocytes treated with PHD2 inhibitors for 72 hours showed the downregulation of genes encoding CYP1A2, CYP2B6, and CYP3A4. The mRNA repressions were accompanied with an increase in erythropoietin protein, a marker of HIF- $\alpha$ stabilization, indicating that HIF- $\alpha$ stabilization was involved in the downregulation of the CYP isoforms. To understand the underlying mechanisms, we assessed the relationship between the expressions of the CYP isoforms and those of their regulating transcription factors [aryl hydrocarbon receptor (AhR), AhR nuclear translocator (ARNT), constitutive androstane receptor (CAR), pregnane $X$ receptor (PXR), and retinoid $X$ receptor (RXR)] in human hepatocytes treated with the HIF- $\alpha$ stabilizers. As a result, the mRNA level of AhR did not decrease,
\end{abstract}

although ARNT expression was repressed. On the other hand, the mRNA expression levels of CAR, PXR, and RXR were repressed and closely associated with those of CYP2B6 and CYP3A4. Although the underlying mechanism of the downregulation for CYP1A2 remains unclear, the presently reported results suggest that the downregulation of CYP2B6 and CYP3A4 via HIF- $\alpha$ stabilization is caused by a decrease in the expressions of CAR, PXR, and RXR.

\section{SIGNIFICANCE STATEMENT}

We showed that hypoxia-inducible factor (HIF)- $\alpha$ stabilization downregulates CYP1A2, CYP2B6, and CYP3A4 using prolyl hydroxylase domain 2 inhibitors, which are HIF- $\alpha$ stabilizers, as a new tool to mimic hypoxia in human hepatocytes. To understand the underlying mechanisms, we assessed the relationship between the expressions of the CYP isoforms and those of their regulating transcription factors. Our findings would contribute to a better understanding of the hypoxia-triggered regulatory mechanism of drug-metabolizing enzymes in human hepatocytes.

\section{Introduction}

Several clinical trials in humans have demonstrated that hypoxemia in patients with cardiorespiratory diseases reduces the plasma clearance or prolongs the plasma half-life of some drugs, such as theophylline (Piafsky et al., 1977; Powell et al., 1978) and antipyrine (Cumming, 1976; Laybourn et al., 1986). Theophylline is primarily biotransformed by CYP1A2 (Sarkar et al., 1992; Zhang and Kaminsky, 1995), and antipyrine is metabolized by multiple CYP isoforms (Engel et al., 1996). One of the mechanisms underlying the decrease in drug clearance is the alteration of hepatic CYP expression by hypoxia, as demonstrated by several experiments (Fradette and Du Souich, 2004; du Souich and Fradette, 2011). For example, rabbits exposed to hypoxia resulted in the

The authors in this work are all employees of Taisho Pharmaceutical Co., Ltd. The authors received no outside funding for this work.

https://doi.org/10.1124/dmd.120.000124.

S This article has supplemental material available at dmd.aspetjournals.org. decreased protein expressions of CYP1A1, CYP1A2, CYP2B4, CYP2C5, and CYP2C16 and the increased protein expression of CYP3A6 in hepatocytes (Fradette et al., 2007). On the other hand, an in vitro study with HepaRG cells under severe hypoxia showed a decrease in the mRNA expressions of CYP1A2, CYP2C9, CYP3A4, and CYP2E1 (Legendre et al., 2009).

Hypoxia-inducible factor (HIF) has been regarded as the most important transcriptional factor activated by hypoxia (Mole et al., 2009; Semenza, 2011) and plays a central role in the regulation of many target genes involved in processes like erythropoiesis, glucose metabolism, and angiogenesis; furthermore, HIF is reportedly associated with the expressions of CYP isoforms. Effectively, the incubation of rabbit hepatocytes with $\mathrm{CoCl}_{2}$, an HIF- $\alpha$ (HIF- $1 \alpha$ and HIF- $2 \alpha$ unless otherwise noted) stabilizer used to mimic hypoxia, stabilized the expression of HIF- $1 \alpha$, and this was followed by an increased expression of CYP3A6 genes by a mechanism in which both HIF-1 and activator protein-1 were implicated (Fradette and du Souich, 2003). On the other hand, HepaRG cells incubated with desferrioxamine, another HIF- $\alpha$ stabilizer,

ABBREVIATIONS: AhR, aryl hydrocarbon receptor; ARNT, AhR nuclear translocator; CAR, constitutive androstane receptor; EPO, erythropoietin; FITC, fluorescein isothiocyanate; GAPDH, glyceraldehyde-3-phosphate dehydrogenase; G-6-P, glucose-6-phosphate; G-6-P-DH, G-6-P dehydrogenase; HIF, hypoxia-inducible factor; IL, interleukin; LC-MS/MS, liquid chromatography-tandem mass spectrometry; LDH, lactate dehydrogenase; MFI, median fluorescence intensity; NF- $\kappa \mathrm{B}$, nuclear factor- $\kappa \mathrm{B}$; PCR, polymerase chain reaction; PHD, prolyl hydroxylase domain; PXR, pregnane X receptor; RT, reverse transcription; RT-PCR, real-time PCR; RXR, retinoid X receptor; WEM, Williams' E medium. 
downregulated the genes of $C Y P 3 A 4$ without the direct binding of HIF$1 \alpha$ to a putative hypoxia response elements site in the $5^{\prime}$-flanking region of CYP3A4 gene (Legendre et al., 2009). The different changes in CYP3A expression by the different putative mechanisms in the studies suggest that the HIF- $\alpha$ stabilization effect on CYP isoforms appears to be dependent on experimental conditions, such as experimental models, animal species, and the extent of hypoxia.

There is an increasing need to use human hepatocytes to elucidate the influence of HIF- $\alpha$ stabilization on CYP expression in humans since human hepatocytes are recommended as an in vitro model to evaluate enzyme induction or downregulation (EMA, 2012; PMDA, 2018; FDA, 2020). However, previous studies have not used human hepatocytes to evaluate the effect of HIF- $\alpha$ stabilization on the expressions of CYP isoforms. Moreover, the mechanism by which HIF- $\alpha$ stabilization downregulates CYP3A4 remains unknown.

Under normoxia conditions, cellular HIF- $\alpha$ is rapidly hydroxylated by HIF prolyl hydroxylase domain (PHD) enzymes (Ivan et al., 2001; Jaakkola et al., 2001), which are nonheme, iron-containing enzymes that hydroxylate the proline residues of HIF- $\alpha$, leading to proteasomal degradation. Cobalt inhibits PHD enzymes by occupying an iron-binding site of the enzymes and the von HippleLindau-binding domain of HIF- $\alpha$ (Yuan et al., 2003), resulting in HIF- $\alpha$ stabilization. Desferrioxamine is also known to stabilize HIF$\alpha$ by chelating iron (Wang and Semenza, 1993) since PHD enzymes require both oxygen and iron for hydroxylation process. Thus, $\mathrm{CoCl}_{2}$ or desferrioxamine has been used for HIF- $\alpha$ stabilization to mimic hypoxia. However, because cobalt is a transition metal, and desferrioxamine is an iron chelator, they might have some effects on other enzymes.

Recently, more attention has been paid to PHD2 inhibitors since the pharmacological inhibition of PHD2, which leads to an increase in erythropoiesis, has therapeutic potential for patients with anemia associated with diseases in kidneys that play a critical role in erythropoiesis (Rabinowitz, 2013). Moreover, PHD2 inhibitors are also expected to be an effective tool for experimentally mimicking hypoxia conditions by stabilizing HIF- $\alpha$ and expected to be more suitable for evaluating the intrinsic effect of HIF- $\alpha$ stabilization on the expressions of CYP isoforms than $\mathrm{CoCl}_{2}$ or desferrioxamine.

The aim of this study was to elucidate the effects of HIF- $\alpha$ stabilization on the expressions of CYP isoforms in human hepatocytes and the mechanism of such effects using PHD2 inhibitors as new tools to mimic hypoxia. We assessed the mRNA levels of CYP1A2, CYP2B6, and CYP3A4, which are regulated via different transcription factors, and the association of the expressions of CYP isoforms with erythropoietin (EPO) protein levels as a marker of HIF- $\alpha$ stabilization after exposure to PHD2 inhibitors. In addition, the mRNA expression levels of the transcription factors that regulate the expressions of the CYP isoforms were investigated to understand the underlying mechanisms.

\section{Materials and Methods}

\section{Chemistry}

All the PHD2 inhibitors (compounds 1-6, Table 1) were synthesized at Taisho Pharmaceutical (Saitama, Japan). The synthesis of the compounds is described in detail in the Supplemental Materials and Methods.

\section{Preparation of Human PHD2}

Human PHD2 enzyme solution was obtained from Taisho Pharmaceutical as follows. Human PHD2 (NP_071334.1) was subcloned into pcDNA3.1/hygro (+) (Thermo Fisher Scientific, Waltham, MA), and the vector was transfected into 293FT cells. Then the cells were harvested using a lysis buffer $(20 \mathrm{mM}$ Tris/ $\mathrm{HCl}$ [pH7.5], $150 \mathrm{mM} \mathrm{NaCl}, 1 \mathrm{mM}$ dithiothreitol, $0.1 \%$ Triton $\mathrm{X}-100$, and proteinase inhibitor cocktail). The cell lysates were sonicated and centrifuged to prepare the enzyme solution.

\section{Materials}

Fluorescein isothiocyanate (FITC) HIF- $1 \alpha$ peptide was purchased from the PEPTIDE INSTITUTE (Osaka, Japan). 2-Oxoglutarate was purchased from Merck (Darmstadt, Germany). Antihydroxylated HIF-1 $\alpha$ antibody was purchased from CST Japan (Tokyo, Japan). Cryopreserved hepatocytes recovery medium, Williams' E medium (WEM), FBS, cell thawing/plating cocktail-A, Geltrex, cell maintenance cocktail-B, $10 \mathrm{mM}$ dexamethasone, a QuantiGene Plex 2.0 Plex Set (12791, Human), a QuantiGene Plex 2.0 Assay Kit, a TaqMan Fast Cells-to-CT kit, and TaqMan q-PCR primer sets for CYP1A2, CYP2B6, CYP3A4, and glyceraldehyde-3-phosphate dehydrogenase (GAPDH) (assay identifications: Hs00167927_m1 for CYP1A2 primer, Hs04183483_g1 for CYP2B6, Hs00604506_m1 for CYP3A4, and Hs02758991_g1 for GAPDH) were purchased from Thermo Fisher Scientific. Phenacetin was purchased from FUJIFILM Wako Pure Chemical Corporation (Osaka, Japan). Acetaminophen, bupropion, and testosterone were purchased from Sigma-Aldrich (St. Louis, MO). Hydroxybupropion and $6 \beta$-hydroxytestosterone were purchased from Corning (Corning, NY). A Cell Counting Kit-8 was purchased from Dojindo Laboratories (Kumamoto, Japan). A lactate dehydrogenase (LDH) detection kit was obtained from Roche (Basel, Switzerland). An EPO ELISA kit was purchased from STEMCELL Technologies (Vancouver, Canada). The deuterium-labeled internal standards for bioanalysis, hydroxybupropion- $\mathrm{d}_{6}$ and $6 \beta$-hydroxytestosterone- $\mathrm{d}_{7}$, were purchased from Corning, and $N$-(4-hydroxyphenyl-2,3,5,6-day ${ }_{4}$ )acetamide was purchased from $\mathrm{C} / \mathrm{D} / \mathrm{N}$ Isotopes ( $\mathrm{QC}$, Canada). All other chemicals and reagents were obtained from usual commercial sources and were of the highest commercially available grades. The primary cultured cryopreserved human hepatocytes (lot number Hu8114, a 47-year-old Caucasian female) were purchased from Thermo Fisher Scientific. Pooled human liver microsomes (mixed sex, pool of 50 donors) were purchased from Sekisui XenoTech (Kansas City, KS).

\section{Inhibitory Activity of Human PHD2}

The PHD2 inhibition potentials of compounds 1-6 were evaluated using a PHD2 hydroxylation reaction known as a fluorescence polarization-based assay with a FITC HIF- $1 \alpha$ peptide as a substrate. This method relies on the displacement of 2-oxoglutrate at the binding site by a competitive ligand. The incubation mixture consisted of $16 \mathrm{nM}$ FITC HIF- $1 \alpha$ peptide, $1 \mathrm{ng} / \mu$ l of lysates overexpressing human PHD2, $20 \mathrm{mM}$ Tris- $\mathrm{HCl}$ buffer (pH7.5), $5 \mathrm{mM} \mathrm{KCl}, 1.5 \mathrm{mM}$ $\mathrm{MgCl}_{2}, 10 \mu \mathrm{M} \mathrm{FeSO}_{4}, 2 \mathrm{mM}$ ascorbic acid, $1 \mathrm{mM}$ dithiothreitol, $0.32 \mu \mathrm{M} 2$ oxoglutarate, and one of several concentrations of compounds 1-6. A 20- $\mu 1$ volume of the incubation mixture was incubated in 384-well plates in the dark at $30^{\circ} \mathrm{C}$ for 10 minutes. The reaction was stopped by the addition of $20 \mu$ of a stop solution containing antihydroxylated HIF1- $\alpha$ antibody, $20 \mathrm{mM}$ EDTA, $100 \mathrm{mM}$ Tris- $\mathrm{HCl}$ buffer ( $\mathrm{pH} 7.5$ ), and $240 \mathrm{mM} \mathrm{NaCl}$. The mixtures were well mixed, and the millipolarization values were measured at a 480-nm excitation and a 535-nm emission using EnVision (PerkinElmer, Waltham, MA). The $\mathrm{IC}_{50}$ values were calculated using XLfit version 5.3.0.8 (IDBS, Guildford, UK) and the nonlinear least-squares method.

\section{Cell Cultures and Compound Treatments}

The primary cultured cryopreserved human hepatocytes were thawed at $37^{\circ} \mathrm{C}$ and poured into cryopreserved hepatocytes recovery medium. After centrifugation $(100 \mathrm{~g}, 10$ minutes), the supernatant was discarded, and the pellet was diluted at a density of $0.6 \times 10^{6}$ cells $/ \mathrm{ml}$ with WEM containing $5 \%$ FBS, $1 \mu \mathrm{M}$ dexamethasone, and $3.6 \%$ cell thawing/plating cocktail-A. Viability, which was determined using trypan blue exclusion, was more than $90 \%$. The cell suspension solution was plated in collagen-coated 96-well plates (Corning) at a volume of $125 \mu \mathrm{l} /$ well. After the incubation for 4-6 hours in a humidity atmosphere of $5 \% \mathrm{CO}_{2}$ at $37^{\circ} \mathrm{C}$, the medium was removed, and the cells were overlaid with $0.35 \mathrm{mg} / \mathrm{ml}$ Geltrex in the support medium, which was WEM containing $0.1 \mu \mathrm{M}$ dexamethasone and $4 \%$ cell maintenance cocktail-B. The medium was replaced with the support medium on the next day after the seeding. The plates were maintained in a humidity atmosphere of $5 \% \mathrm{CO}_{2}$ at $37^{\circ} \mathrm{C}$ for 3 days. Then the cells were treated for approximately 72 hours with one of the PHD2 inhibitors, omeprazole ( $50 \mu \mathrm{M}$, a positive control for CYP1A2 induction), 
TABLE 1

Structures of the PHD2 inhibitors and inhibitory activities for human PHD2

Compound<smiles>O=C(O)CNC(=O)C1=C(O)CC2(COC2)N(Cc2ccc(-c3ccccc3)cc2)C1=O</smiles><smiles>O=C(O)CNC(=O)C1=C(O)C2(CC2)CN(Cc2ccc(C(F)(F)F)cc2)C1=O</smiles><smiles>O=C(O)CNC(=O)C1=C(O)CCN(Cc2ccc(OC(F)(F)F)c(Cl)c2)C1=O</smiles><smiles>COc1ccc(-c2ccc(C(C)(C)NC(=O)c3cnc(-c4ncn[nH]4)cc3OC)cn2)cc1</smiles><smiles>O=C(NCc1ccc2c(c1)CCO2)c1ccc(-c2ncn[nH]2)nc1</smiles>

phenobarbital (1000 $\mu \mathrm{M}$, a positive control for CYP2B6 induction), rifampicin (10 $\mu \mathrm{M}$, a positive control for CYP3A induction), tamoxifen $(50 \mu \mathrm{M}$, a positive control for cell toxicity), or $0.1 \%$ DMSO as a vehicle control in the support medium; the final DMSO concentration in the support medium was $0.1 \%$ except for cell viability assay, in which the final DMSO concentration was $0.5 \%$. The medium containing the test compounds or the vehicle control was replaced daily, and the removed medium was stored at $4^{\circ} \mathrm{C}$ for the measurement of $\mathrm{LDH}$ levels or at from $-40^{\circ} \mathrm{C}$ to $-20^{\circ} \mathrm{C}$ for the measurement of EPO protein levels. 


\section{Evaluation of CYP Enzyme Activities}

The enzyme activities of CYP1A2, CYP2B6, and CYP3A in human hepatocytes treated with compound 1 or positive controls (omeprazole, phenobarbital, or rifampicin) were measured. After the treatment of the compounds for 72 hours in the condition described in the Cell Cultures and Compound Treatments section, the cells were washed with the support medium two times and then were incubated with $100 \mu \mathrm{M}$ phenacetin for CYP1A2, $500 \mu \mathrm{M}$ bupropion for CYP2B6, or $200 \mu \mathrm{M}$ testosterone for $\mathrm{CYP} 3 \mathrm{~A}$ in the support medium at $37^{\circ} \mathrm{C}$ for 60 minutes. After the incubation period, a 50- $\mu 1$ aliquot of medium was removed from each well and added to $100 \mu \mathrm{l}$ of acetonitrile with $0.1 \%$ formic acid containing the internal standard (1.5 $\mu \mathrm{M} \mathrm{N}$-(4-hydroxyphenyl-2,3,5,6- $\left.\mathrm{d}_{4}\right)$-acetamide, $0.75 \mu \mathrm{M}$ hydroxybupropion- $\mathrm{d}_{6}$, or $5 \mu \mathrm{M} 6 \beta$-hydroxytestosterone- $\mathrm{d}_{7}$ ). The mixture was centrifuged for 10 minutes at $3974 \mathrm{~g}$, and the supernatant was subjected to liquid chromatography-tandem mass spectrometry (LC-MS/MS) to determine acetaminophen, hydroxybupropion, and $6 \beta$-hydroxytestosterone, which were probe metabolites of phenacetin, bupropion, and testosterone, respectively.

\section{Evaluation of CYP mRNA Expression}

The mRNA expression in human hepatocytes was analyzed using a realtime polymerase chain reaction (RT-PCR) method for compound 1 or using a QuantiGene Plex 2.0 assay for compounds 2-6.

RT-PCR Assay. The mRNA expression levels of CYP1A2, CYP2B6, CYP3A4, and the endogenous control GAPDH in human hepatocytes treated with compound $1(1$ and $10 \mu \mathrm{M})$ were measured using an RT-PCR method. The RT-PCR was performed using the TaqMan Fast Cells-to-CT kit according to the manufacturer's instructions. Briefly, after the treatment of compound 1 for 72 hours in the condition described in the Cell Cultures and Compound Treatments section, the cells were lysed with lysis solution containing DNase I. The cell lysate was mixed with reverse-transcription (RT) master mix containing RT buffer and RT enzyme. The mixture was incubated at $37^{\circ} \mathrm{C}$ for 60 minutes and subsequently at $95^{\circ} \mathrm{C}$ for 5 minutes to synthesize cDNA and then kept at $4{ }^{\circ} \mathrm{C}$ until use. The cDNA samples were mixed with each PCR cocktail, including a PCR master mix and TaqMan probe in the PCR plate, and amplification was performed using the 7500 Fast RT-PCR system (Thermo Fisher Scientific). The relative mRNA expressions were determined by dividing the mRNA expression of the target gene normalized to the GAPDH gene expression for the compound 1-treated wells by that of the vehicle control wells, which is known as the comparative cycle threshold $\left(\Delta \Delta \mathrm{C}_{\mathrm{T}}\right)$ method.

QuantiGene Plex 2.0 Assay. The mRNA expression levels of CYP1A2, CYP2B6, CYP3A4, transcription factors [aryl hydrocarbon receptor (AhR), AhR nuclear translocator (ARNT), constitutive androstane receptor (CAR), pregnane $\mathrm{X}$ receptor (PXR), and retinoid $\mathrm{X}$ receptor (RXR)], and TATA box binding protein (an endogenous control) in human hepatocytes treated with one of the PHD2 inhibitors (compounds 2-5: $0.1,1$, or $10 \mu \mathrm{M}$; compound 6: $0.3,3$, or $30 \mu \mathrm{M}$ ) were measured using a QuantiGene Plex 2.0 assay with the QuantiGene Plex 2.0 Plex Set and the QuantiGene Plex 2.0 Assay Kit according to the manufacturer's instructions. Briefly, after the treatment of compounds 2-6 for 72 hours in the condition described in the Cell Cultures and Compound Treatments section, the cells were lysed with a lysis mixture containing proteinase $\mathrm{K}$. Then the cell lysates were mixed with a lysis mixture containing proteinase $\mathrm{K}$, blocking reagent, capture beads, and a 2.0 probe set designed to capture the target RNA molecules on the beads. The mixture was incubated at $54^{\circ} \mathrm{C}$ for 22 hours for hybridization. After the hybridization, the signal amplification of the RNA samples was conducted using a stepwise reaction mediated by the DNA amplification molecules. First, the beads were washed and incubated with the preamplifier solution at $50^{\circ} \mathrm{C}$ for 1 hour. Next, the same procedure was conducted using the amplifier solution followed by the label probe solution. Finally, the beads were washed, and this was followed by the incubation with streptavidin phycoerythrin at room temperature for 30 minutes. The resulting fluorescence signal associated with individual capture beads was read on a Luminex 200 system (Luminex, Austin, TX) and was reported as the median fluorescence intensity (MFI). The MFI for each target gene was normalized to that of the TATA box binding protein gene. The adjusted MFI values were used to determine the relative mRNA expression by dividing the average of the normalized MFI of the wells treated with the compounds $2-6$ by that of the vehicle control wells.

\section{Cell Toxicity}

Cell toxicity was evaluated according to cell viability for compound 1 and the release of LDH into the medium for compounds 2-6.

Cell Viability Assay. The cell viability for compound 1 was measured at concentrations of $2.5,5,10,20,40$, and $80 \mu \mathrm{M}$ using the Cell Counting Kit- 8 according to the manufacturer's protocols. Briefly, after the treatment of compound 1 for 72 hours in the condition described in the Cell Cultures and Compound Treatments section, an aliquot of medium was removed from each well, and this was followed by the addition of Cell Counting Kit- 8 (final, $10 \% \mathrm{v} / \mathrm{v}$ ); the plate was then incubated in a humidity atmosphere of $5 \% \mathrm{CO}_{2}$ at $37^{\circ} \mathrm{C}$ for approximately 2 hours. After the incubation, the absorbance at $450 \mathrm{~nm}$ with a reference at $650 \mathrm{~nm}$ was measured using a microplate spectrophotometer (BioRad, Hercules, CA). Cell viability was calculated as follows: $\%$ viability $=$ (mean absorbance in compound 1-treated well - blank well)/(mean absorbance in vehicle control well - blank well) $\times 100$.

LDH Assay. The cellular toxicity was assessed by measuring LDH leakage into the culture medium. The LDH levels in the medium from hepatocytes treated with compounds $2-6$ (compounds $2-5,10 \mu \mathrm{M}$; compound $6,30 \mu \mathrm{M}$ ) or tamoxifen $(50 \mu \mathrm{M})$ were assayed using an LDH detection kit according to the manufacturer's instructions. Briefly, aliquots $(30 \mu \mathrm{l})$ of the medium were added to $30 \mu l$ of the reaction mixture (bottle $1 /$ bottle $2=1 / 45$, v/v) in a 96 -well plate, and the plate was incubated in the dark for 30 minutes at room temperature. After the incubation, the reaction was stopped by the addition of a volume of $25 \mu \mathrm{l}$ of $1 \mathrm{M} \mathrm{HCl}$. Then the absorbance at $490 \mathrm{~nm}$ was measured using an ARVO SX (PerkinElmer). The cellular toxicity was evaluated based on the percentage of LDH released into the medium. Tamoxifen caused the release of almost all the LDH during 0-48 hours because the LDH levels in the medium at 48-72 hours were dramatically decreased, meaning that almost all the cells had died; thus, the total amount of LDH released into the medium during 0-72 hours after treatment with tamoxifen was regarded as being equivalent to $100 \% \mathrm{LDH}$ in the cells.

\section{Reversible Inhibition of CYP Enzymes}

The incubation mixture $(0.3 \mathrm{ml})$ consisted of $0.1 \mathrm{mg}$ protein $/ \mathrm{ml}$ human liver microsomes, $100 \mathrm{mM}$ phosphate buffer ( $\mathrm{pH} 7.4$ ), $99 \mathrm{mM} \mathrm{KCl}, 2.4 \mathrm{mM} \mathrm{MgCl}_{2}$, $1.4 \mathrm{mM}$ glucose-6-phosphate (G-6-P), $0.17 \mathrm{U} / \mathrm{ml}$ glucose-6-phosphate dehydrogenase (G-6-P-DH), each probe substrate $(40 \mu \mathrm{M}$ phenacetin for CYP1A2, $145 \mu \mathrm{M}$ bupropion for CYP2B6, or $50 \mu \mathrm{M}$ testosterone for CYP3A), and $10 \mu \mathrm{M}$ of compound 1. After preincubation for 5 minutes, the reactions were initiated by the addition of a $\beta$-NADP ${ }^{+}$solution (final, $0.15 \mathrm{mM}$ ). All incubations were conducted at $37^{\circ} \mathrm{C}$ for 10 minutes and were terminated by the addition of $0.3 \mathrm{ml}$ of acetonitrile. After adding $30 \mu \mathrm{l}$ of acetonitrile containing each internal standard [6 $\mu \mathrm{M} N$-(4-hydroxyphenyl-2,3,5,6- $\mathrm{d}_{4}$ )-acetamide, $1.5 \mu \mathrm{M}$ hydroxybupropion$\mathrm{d}_{6}$, or $20 \mu \mathrm{M} 6 \beta$-hydroxytestosterone- $\left.\mathrm{d}_{7}\right]$, the resultant precipitated proteins were removed by centrifugation at $3974 \mathrm{~g}$ for 10 minutes at $4^{\circ} \mathrm{C}$ to determine the probe metabolites using LC-MS/MS

\section{Time-Dependent Inhibition of CYP Enzymes}

Human liver microsomes were preincubated with compound 1 to allow for the generation of intermediates that may inhibit CYP isoforms (first incubation). After the first incubation, the aliquots of microsomes were transferred to the incubation mixtures containing probe substrates, and subsequent incubation was performed to measure the marker CYP activities (second incubation). The first incubation mixture $(0.3 \mathrm{ml})$ consisted of $0.5 \mathrm{mg}$ protein $/ \mathrm{ml}$ human liver microsomes, $100 \mathrm{mM}$ phosphate buffer (pH 7.4), $98 \mathrm{mM} \mathrm{KCl}, 2.4 \mathrm{mM} \mathrm{MgCl}_{2}, 1.4 \mathrm{mM} \mathrm{G-6-P}$, $0.17 \mathrm{U} / \mathrm{ml}$ G-6-P-DH, and compound $1(10 \mu \mathrm{M})$. After prewarming at $37^{\circ} \mathrm{C}$ for 5 minutes, the reaction for 0 or 30 minutes was initiated by the addition of distilled water or $\beta-\mathrm{NADP}^{+}$(final, $0.15 \mathrm{mM}$ ), respectively. At 0 or 30 minutes after the initiation of the first incubation at $37^{\circ} \mathrm{C}$, the aliquots of the first incubation mixtures $(30 \mu \mathrm{l})$ were transferred to the second incubation mixtures to initiate the incubation for each marker activity. The second incubation mixture $(0.3 \mathrm{ml})$ consisted of $0.05 \mathrm{mg}$ protein/ml human liver microsomes, $91 \mathrm{mM}$ phosphate buffer (pH 7.4), $9.8 \mathrm{mM} \mathrm{KCl}, 2.2 \mathrm{mM} \mathrm{MgCl}$, $1.3 \mathrm{mM} \mathrm{G-6-P,} 0.16 \mathrm{U} / \mathrm{ml} \mathrm{G-6-P-}$ $\mathrm{DH}, 0.17 \mathrm{mM} \beta-\mathrm{NADP}^{+}$, and each probe substrate $(200 \mu \mathrm{M}$ phenacetin for CYP1A2, $700 \mu \mathrm{M}$ bupropion for CYP2B6, or $250 \mu \mathrm{M}$ testosterone for CYP3A). The second incubation was conducted at $37^{\circ} \mathrm{C}$ for 10 minutes and was terminated by the addition of $0.3 \mathrm{ml}$ of acetonitrile. After adding $30 \mu \mathrm{l}$ of acetonitrile 
containing each internal standard $\left[6 \mu \mathrm{M} N\right.$-(4-hydroxyphenyl-2,3,5,6- $\left.\mathrm{d}_{4}\right)$-acetamide, $1.5 \mu \mathrm{M}$ hydroxybupropion- $\mathrm{d}_{6}$, or $20 \mu \mathrm{M} 6 \beta$-hydroxytestosterone- $\left.\mathrm{d}_{7}\right]$, the resultant precipitated proteins were removed by centrifugation at $3974 \mathrm{~g}$ for 10 minutes at $4^{\circ} \mathrm{C}$ to determine the probe metabolites using LC-MS/MS.

\section{Quantitative Measurement of EPO}

EPO protein levels in media of human hepatocytes treated with one of the PHD2 inhibitors were measured using a Human EPO ELISA Kit according to the manufacturer's instructions. First, the medium samples and the biotinylated anti-EPO antibodies were incubated in a 96-well microtiter plate precoated with an anti-EPO monoclonal capture antibody. Then the wells were incubated with streptavidin-peroxidase conjugate, which bound to the biotinylated anti-EPO antibody. Finally, tetramethylbenzidine substrate solution was added, and color development was terminated after 15 minutes of incubation by the addition of the stop solution ( $0.5 \mathrm{M}$ sulphuric acid). The color intensity was measured spectrophotometrically using a SpectraMax Plus384 (Molecular Devices, San Jose, CA) at $450 \mathrm{~nm}$ with $620 \mathrm{~nm}$ as a reference. The EPO protein concentration was totaled every 24 hours to calculate the total EPO secretion over 72 hours.

\section{LC-MS/MS}

An LC-MS/MS system consisting of an API4000 triple quadrupole mass spectrometer (AB SCIEX, Framingham, MA), an LC-20AD system (Shimadzu, Kyoto, Japan), and a CTC-PAL auto injector (CTC Analytics AG, Zwingen, Switzerland) was employed. The chromatographic separations were performed on a Shimadzu Shim-pack XR-ODS column $(2.2 \mu \mathrm{m}, 30 \times 3.0 \mathrm{~mm}$ I.D.; Shimadzu $)$ at $50^{\circ} \mathrm{C}$ in a linear gradient elution mode with a mobile phase that consisted of a mixture of $\mathrm{A}$ ( $0.1 \%$ formic acid) and $\mathrm{B}$ (acetonitrile). The gradient conditions for elution of acetaminophen were as follows: $2 \%-95 \%$ B (0.00-1.00 minutes), $98 \%$ B (1.00-1.20 minutes), and 2\% B (1.20 minutes). For hydroxybupropion, the gradient conditions were as follows: $2 \%-60 \% \mathrm{~B}(0.00-1.00$ minutes), $98 \% \mathrm{~B}$ (1.00-1.20 minutes), and 2\% B (1.20 minutes). The gradient conditions for $6 \beta$ hydroxytestosterone were as follows: $2 \%-40 \%$ B $(0.00-1.60$ minutes $), 98 \%$ B (1.60-1.80 minutes), and 2\% B (1.80 minutes). Analyte concentrations were calculated from the ratio of the analyte peak area to the internal standard peak area, as interpreted from the calibration line using Analyst 1.6.1 software (AB SCIEX).

\section{Statistical Analysis}

The statistical analysis of the data was performed using SAS version 9.2 (SAS Institute, Cary, NC) using Dunnett's multiple comparisons test to compare CYP mRNA expression or enzyme activity in human hepatocytes treated with PHD2 inhibitors with that in the control cells. $P$ values of less than 0.05 were considered statistically significant.

\section{Results}

Inhibitory Activity for PHD2. The PHD2 inhibitors used in this study were structurally diverse and were classified into two groups (Table 1): glycinamide (compounds 1-4) and triazolylpyridine (compounds 5 and 6). They showed inhibitory effects for human PHD2 with $\mathrm{IC}_{50}$ values ranging from 27 to $180 \mathrm{nM}$ (Table 1). According to their $\mathrm{IC}_{50}$ values, the PHD2 inhibitors were divided into two groups as "weak inhibitors (compounds 3 and 4)" and "strong inhibitors (compounds 1, 2, 5, and 6)."

Effect of Compound 1 on Enzyme Activities and mRNA Expressions of CYP1A2, CYP2B6, and CYP3A in Human Hepatocytes. Enzyme activities of CYP1A2, CYP2B6, and CYP3A in hepatocytes were evaluated by measuring the probe metabolites in the medium; although the possible underestimation of total metabolite formation could not be ruled out because no measurement of metabolites was left in the cell pellet, the metabolites were measurable with enough levels to evaluate the CYP activities. As demonstrated in Fig. 1A, treatment with compound 1, a strong PHD2 inhibitor, in human hepatocytes for 72 hours resulted in a dose-dependent decrease in the activities of CYP1A2, CYP2B6, and CYP3A. CYP1A2-dependent phenacetin O-deethylation, CYP2B6-dependent bupropion hydroxylation, and
A Enzyme activity

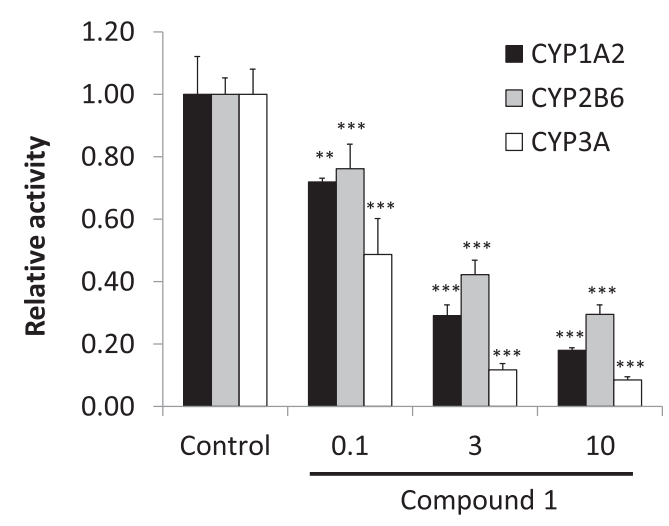

B mRNA expression

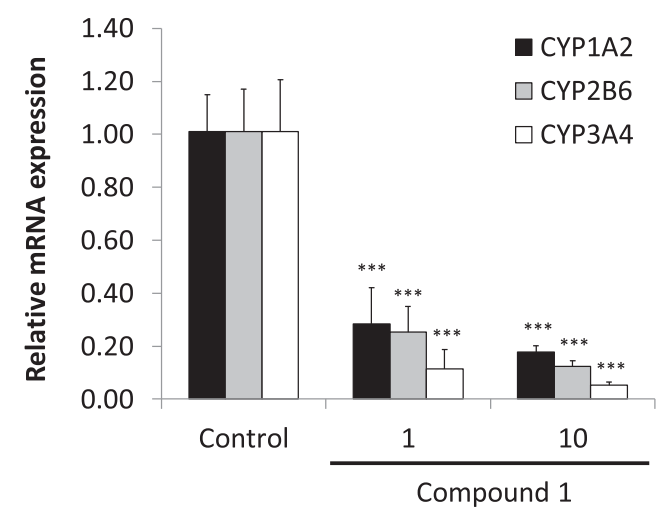

Fig. 1. Effect of compound 1 on enzyme activities (A) and mRNA expressions (B) of CYP1A2, CYP2B6, and CYP3A in human hepatocytes. Human hepatocytes were incubated with compound 1 or the vehicle control, which was replaced daily for 72 hours. Data represent the mean \pm S.D. $(n=3)$. Dunnett's multiple comparisons test was performed by comparing the compound 1-treated cells with the vehicle-treated cells $(* * P<0.01 ; * * * P<0.001)$.

CYP3A-depnedent testosterone $6 \beta$-hydroxylation were decreased by up to $82 \%, 71 \%$, and $92 \%$ compared with the vehicle control at the highest concentration $(10 \mu \mathrm{M})$, respectively. On the other hand, the treatment of cultured human hepatocytes with positive control CYP inducers caused appropriate increases in CYP enzyme activity. Omeprazole $(50 \mu \mathrm{M})$, phenobarbital $(1000 \mu \mathrm{M})$, and rifampicin $(10 \mu \mathrm{M})$ caused increases of 40.3-fold, 33.5-fold, and 3.5-fold in the CYP1A2, CYP2B6, and CYP3A activities, respectively. In addition, an increasing dose of compound 1 reduced the mRNA expressions of CYP1A2, CYP2B6, and CYP3A4 (Fig. 1B).

Cytotoxicity of the PHD2 Inhibitors in Human Hepatocytes. The cytotoxicity of the PHD2 inhibitors in human hepatocytes was evaluated. The cellular morphology of the cells treated with the PHD2 inhibitors did not show cellular damage. Compound 1 exerted no toxic effects on cell viability at doses of up to $80 \mu \mathrm{M}$ after 72 hours of exposure in human hepatocytes (Fig. 2). In addition, as shown in Table 2, no obvious changes in LDH release during the 72 hours after administration were observed in human hepatocytes treated with compounds 2-6 compared with those in the vehicle control. In contrast, LDH release from human hepatocytes with $50 \mu \mathrm{M}$ of tamoxifen, a positive control for cell toxicity, increased largely by as much as $66 \%$ during the first 24 hours and $33 \%$ during $24-48$ hours but thereafter decreased dramatically to $1 \%$ during $48-72$ hours, and the morphology 


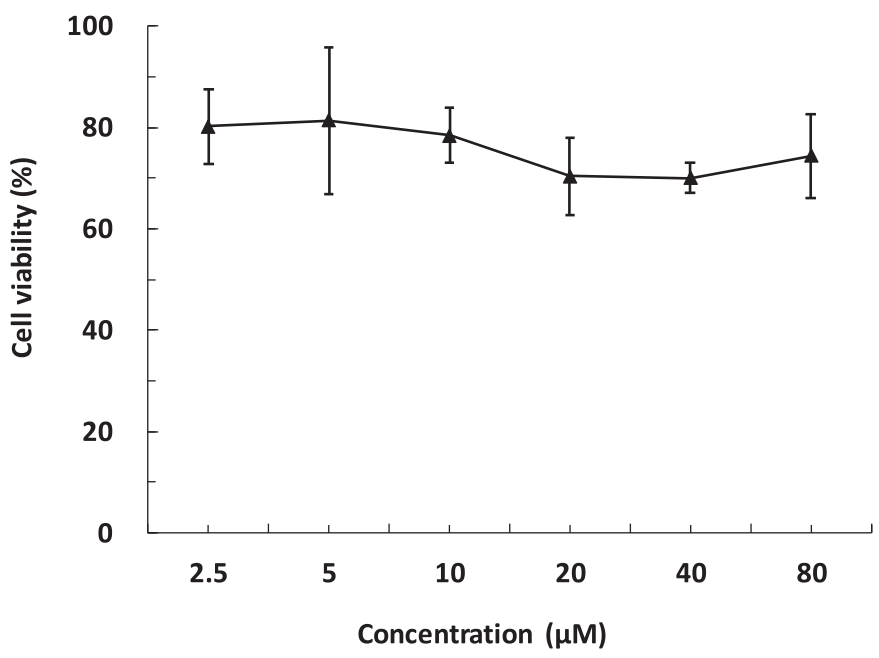

Fig. 2. Cell viability after treatment with compound 1 . Human hepatocytes were incubated with several concentrations of compound 1, which was replaced daily for 72 hours. Cell viability was measured using the Cell Counting Kit-8. Data represent the mean \pm S.D. $(n=4)$.

of the cells treated with tamoxifen showed massive cellular damage (unpublished data).

Inhibitory Effect of Compound 1 on CYP1A2, CYP2B6, and CYP3A Enzyme Activities in Both Reversible and Time-Dependent Inhibition. The inhibitory potential of compound 1 on CYP1A2, CYP2B6, and CYP3A activities was investigated to confirm that the observed decrease in activities of the CYP isoforms in human hepatocytes was independent of CYP enzyme inhibition. Human liver microsomes incubated with each CYP substrate in the presence or absence of compound 1 did not have an inhibitory effect on CYP1A2, CYP2B6, or CYP3A enzyme activities in both a reversible and time-dependent manner (Table 3).

Effect of the PHD2 Inhibitors on CYP1A2, CYP2B6, and CYP3A4 mRNA Expressions in Human Hepatocytes. To confirm whether the downregulation of gene expression observed in compound 1 (Fig. 1B) was associated with PHD2 inhibition as a class effect, the effects of the other structurally diverse PHD2 inhibitors on the mRNA expressions of CYP1A2, CYP2B6, and CYP3A4 were evaluated. The mRNA expression analysis of human hepatocytes treated with the PHD2 inhibitors (compounds 2-6) for 72 hours showed a downregulation of genes encoding CYP1A2, CYP2B6, and CYP3A4 except for the effect of compound 4 on CYP3A4 mRNA (Fig. 3). However, the degree and the dose dependence of the downregulation differed between the weak PHD2 inhibitors (compounds 3 and 4) and the strong PHD2 inhibitors (compounds 2, 5, and 6). The CYP1A2 mRNA level was decreased by both the weak and the strong PHD2 inhibitors as the dose of inhibitor was increased. For both CYP2B6 and CYP3A4, the strong PHD2 inhibitors repressed the mRNA levels in a dose-dependent manner, although a clear dose dependence was not observed with the weak PHD2 inhibitors.

Relationships of mRNA Expressions of CYP1A2, CYP2B6, and CYP3A4 with EPO Production in Human Hepatocytes Treated with PHD2 Inhibitors. We investigated the relationships between the mRNA expression levels of CYP1A2, CYP2B6, and CYP3A4 and the EPO protein levels in the media of human hepatocytes treated with the PHD2 inhibitors for 72 hours. As demonstrated in Fig. 4, A and B, CYP1A2 mRNA repression was accompanied with an increase in the EPO levels for all the PHD2 inhibitors. On the other hand, the relationships of CYP2B6 and CYP3A4 expressions with EPO protein production differed between the strong and the weak PHD2 inhibitors.
TABLE 2

LDH release after exposure to PHD2 inhibitors in human hepatocytes

The total amount of LDH released into the medium for $72 \mathrm{~h}$ from cells treated with tamoxifen ( $50 \mu \mathrm{M}$, a positive control for cell toxicity) was regarded as equivalent to $100 \% \mathrm{LDH}$ in cells.

\begin{tabular}{lcccc}
\hline \multirow{2}{*}{ Compound } & Conc. $(\mu \mathrm{M})$ & \multicolumn{3}{c}{ LDH Release $(\%)^{a}$} \\
\cline { 3 - 5 } & & $0-24 \mathrm{~h}$ & $24-48 \mathrm{~h}$ & $48-72 \mathrm{~h}$ \\
\hline \multirow{2}{*}{ Control (0.1\% DMSO) } & - & 3.9 & 2.9 & 1.7 \\
2 & 10 & 3.7 & 3.0 & 2.5 \\
3 & 10 & 3.0 & 2.0 & 2.5 \\
4 & 10 & 3.6 & 2.0 & 1.9 \\
5 & 10 & 3.7 & 5.7 & 6.3 \\
6 & 30 & 3.2 & 2.0 & 2.9 \\
\hline
\end{tabular}

${ }^{a}$ Each value represents the mean $(n=3)$

As shown in Fig. 4, C and E, the CYP2B6 and CYP3A4 expressions were repressed as the EPO levels increased in the presence of the strong PHD2 inhibitors (compounds 1, 2, 5, and 6), whereas these expressions were not repressed EPO-dependently in the presence of the weak PHD2 inhibitors (compounds 3 and 4) in Fig. 4, D and F, although both the strong and the weak PHD2 inhibitors produced EPO. When compared at the same level of EPO production, the extent of CYP2B6 and CYP3A4 repression via the weak PHD2 inhibitors was smaller than that via the strong PHD2 inhibitors.

Correlations of mRNA Repressions of CYP1A2, CYP2B6, and CYP3A4 with the Levels of Corresponding Transcription Factors in Human Hepatocytes Treated with the PHD2 Inhibitors. To understand the mechanism underlying the downregulation of each CYP enzyme in human hepatocytes treated with the PHD2 inhibitors, we investigated the effect of the PHD2 inhibitors on the expressions of the transcription factors that regulate CYP1A2, CYP2B6, and CYP3A4 expressions. Since the heterodimers of "AhR and ARNT," "CAR and RXR," and "PXR and RXR" are known to regulate the gene expressions of CYP1A2, CYP2B6, and CYP3A4, respectively, the correlations of mRNA expression between each CYP isoform and the corresponding transcription factor in human hepatocytes after exposure to the PHD2 inhibitors were assessed. The expression of AhR was not influenced by the PHD2 inhibitors (Fig. 5A). On the other hand, the expressions of ARNT, CAR, PXR, and RXR were repressed to a minimum value of $0.655,0.0986,0.500$, and 0.386 by compound 5 at $10 \mu \mathrm{M}$, respectively (Fig. 5, B-F). The correlation coefficient (r) was calculated between the mRNA expression of each CYP isoform and that of the corresponding transcription factor. As a result, close correlations were observed between CYP1A2 and ARNT (Fig. 5B, $r=0.84$ ), CYP2B6 and CAR (Fig. 5C, $r=0.89$ ), CYP2B6 and RXR (Fig. 5D, $r=0.87$ ), CYP3A4 and PXR (Fig. 5E, $r=0.75$ ), and CYP3A4 and RXR (Fig. 5F, $r=0.80$ ), whereas no correlation was observed between CYP1A2 and AhR (Fig. 5A, $r=-0.10$ ).

\section{Discussion}

In this study, we investigated the effect of HIF- $\alpha$ stabilization on the expressions of CYP1A2, CYP2B6, and CYP3A4 in primary human hepatocytes using novel PHD2 inhibitors as the HIF- $\alpha$ stabilizers to mimic hypoxia. To understand their underlying mechanisms, moreover, our efforts were directed to elucidate the relationship between the expressions of the CYP isoforms and the transcription factors (AhR, ARNT, CAR, PXR, and RXR) that regulate the expressions of the CYP isoforms.

The PHD2 inhibitors used in this study were structurally diverse with two distinct motifs, glycinamide and triazolylpyridine, and were divided into "weak inhibitors" and "strong inhibitors" according to their $\mathrm{IC}_{50}$ values. We showed that compound 1, a strong PHD2 inhibitor, reduced the 
TABLE 3

Inhibitory effects of compound $1(10 \mu \mathrm{M})$ on CYP1A2, CYP2B6, and CYP3A enzyme activities in both reversible and time-dependent inhibitions in human microsomes

\begin{tabular}{lccc}
\hline \multirow{2}{*}{ Mechanism } & \multicolumn{3}{c}{ \% Inhibition $^{a}$} \\
\cline { 2 - 4 } & CYP1A2 & CYP2B6 & CYP3A \\
\hline Reversible inhibition $_{\text {Time-dependent inhibition }^{b}}$ & 4.0 & 2.4 & -3.2 \\
& -7.2 & -2.3 & -10.7 \\
\hline
\end{tabular}

${ }^{a}$ Each value represents the mean $(n=3)$

${ }^{b}$ The time-dependent inhibition was indicated as the difference in the percent inhibition between with and without the first incubation.

activities of CYP1A2, CYP2B6, and CYP3A in human hepatocytes without inhibiting their enzyme activities. The decrease in CYP1A2, CYP2B6, and CYP3A activities was concomitant with the repression of their mRNA, indicating that the decrease in the expression levels of CYP1A2, CYP2B6, and CYP3A4 leads to the decrease in their activities. Further study demonstrated that the incubation of human hepatocytes with other PHD2 inhibitors also repressed the CYP1A2, CYP2B6, and CYP3A4 mRNA levels without causing any cellular damage, although the extent and the dose dependence of the repression caused by the weak PHD2 inhibitors were smaller than those caused by the strong PHD2 inhibitors. These results suggest that the downregulation of CYP enzymes is associated with HIF- $\alpha$ stabilization caused by the PHD2 inhibitors. To confirm the involvement of HIF- $\alpha$ stabilization, we showed that the decrease in CYP1A2, CYP2B6, and CYP3A4 mRNA was accompanied with an increase in EPO protein levels, a marker of HIF- $\alpha$ stabilization, when human hepatocytes were incubated with the PHD2 inhibitors. This supports the idea that the downregulation of genes encoding CYP1A2, CYP2B6, and CYP3A4 is caused by HIF- $\alpha$ stabilization. In the case of compound 5, the EPO levels at $1 \mu \mathrm{M}$ were higher than those at $10 \mu \mathrm{M}$ despite a dose-dependent decrease in the mRNA expressions of CYP isoforms (Fig. 4, A, C, and E). Since compound 5 is the strongest PHD2 inhibitor, the EPO production seems to reach maximum and flatten out between 1 and $10 \mu \mathrm{M}$. Although the EPO levels associated with the weak PHD2 inhibitors were comparable to those associated with the strong PHD2 inhibitors, the weak inhibitors did not repress CYP2B6 or CYP3A4 to the same extent as the strong inhibitors. The reason for the reduced repression of CYP2B6 and CYP3A4 by the weak PHD2 inhibitors despite the comparable EPO production is poorly understood, but the different kinetics of HIF- $\alpha$ stabilization between the weak PHD2 inhibitors and the strong PHD2 inhibitors and, in addition, the different mechanisms of downregulation between CYP1A2 and CYP2B6/CYP3A4, as discussed in the next paragraphs, might be involved.

The mRNA expressions of CYP1A2, CYP2B6, and CYP3A4 are modulated by transcription factors, such as AhR, ARNT, CAR, PXR, and RXR (Rushmore and Kong, 2002). AhR binds to ARNT, and the heterodimer binds to xenobiotic response elements in the promoter regions of the CYP1A2 gene, resulting in an increased formation of CYP1A2 mRNA. CAR and PXR, respectively, form a heterodimer with $\mathrm{RXR}$, and the heterodimer activates the transcription of $C Y P 2 B 6$ and CYP3A4 by binding to the promoters, respectively. Thus, we investigated the effect of HIF- $\alpha$ stabilization on the expressions of transcription factors to clarify the underlying mechanism of the CYP downregulation. The incubation of human hepatocytes with the PHD2 inhibitors did not alter the mRNA levels of AhR, whereas it repressed the ARNT mRNA expression. Although the mRNA expression of ARNT was closely correlated with that of CYP1A2, the repression of ARNT was weaker than that of CYP1A2. Therefore, it would be difficult to explain the repression of CYP1A2 solely by that of ARNT. Considering ARNT is a heterodimerization partner for both HIF- $\alpha$ and AhR, another
A CYP1A2

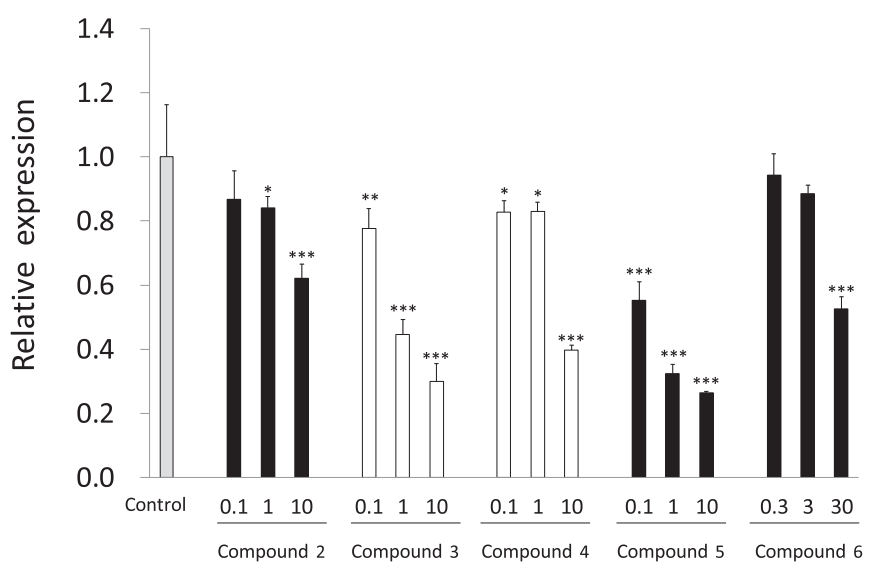

\section{B CYP2B6}

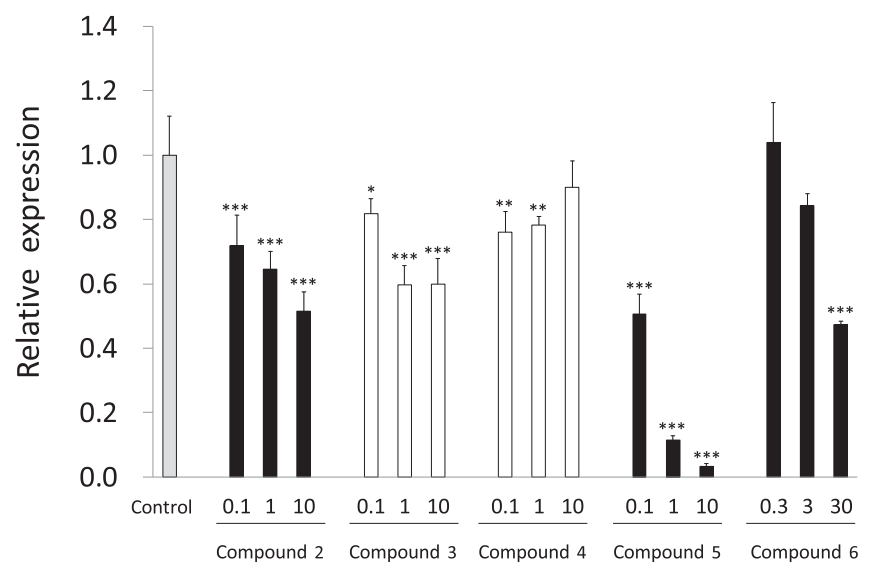

\section{CYP3A4}

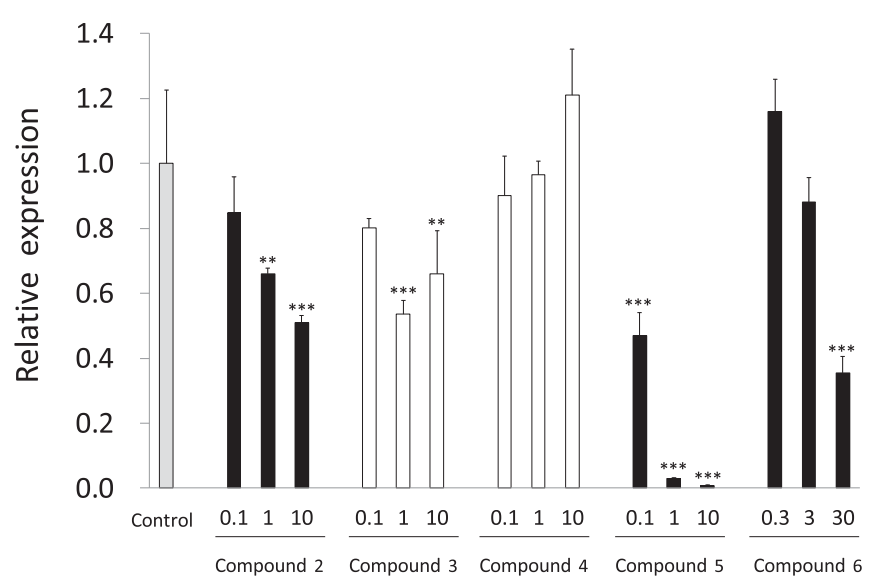

Fig. 3. Effects of the PHD2 inhibitors on CYP1A2 (A), CYP2B6 (B), and CYP3A4 (C) mRNA expressions. Human hepatocytes were incubated with the PHD2 inhibitors (compounds $2-5: 0.1,1$, and $10 \mu \mathrm{M}$; compound $6: 0.3$, 3, and $30 \mu \mathrm{M}$ ) or a vehicle control, which were replaced daily for 72 hours. Data represent the mean \pm S.D. $(n=3)$. The closed and open bars show the strong PHD2 inhibitors (compounds 2, 5, and 6) and weak PHD2 inhibitors (compounds 3 and 4), respectively. Dunnett's multiple comparisons test was performed by comparing the PHD2 inhibitor-treated cells with the vehicle-treated cells $(* P<0.05 ; * * P<0.01$; $* * * P<0.001)$. 
A CYP1A2 (strong PHD2 inhibitors)

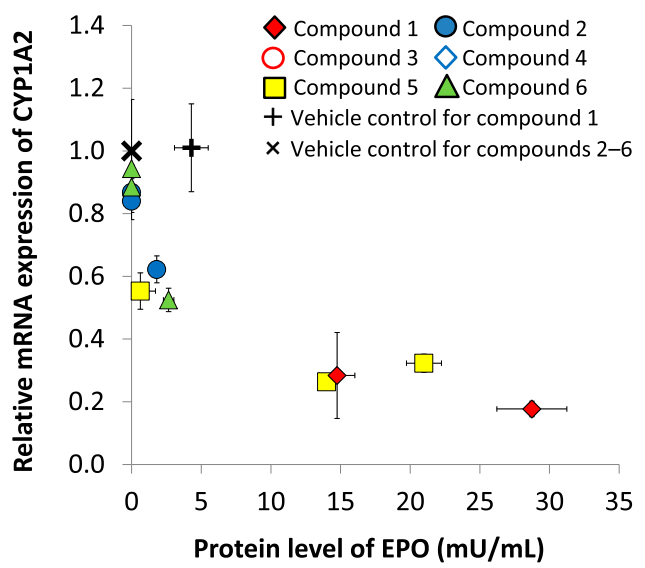

C CYP2B6 (strong PHD2 inhibitors)

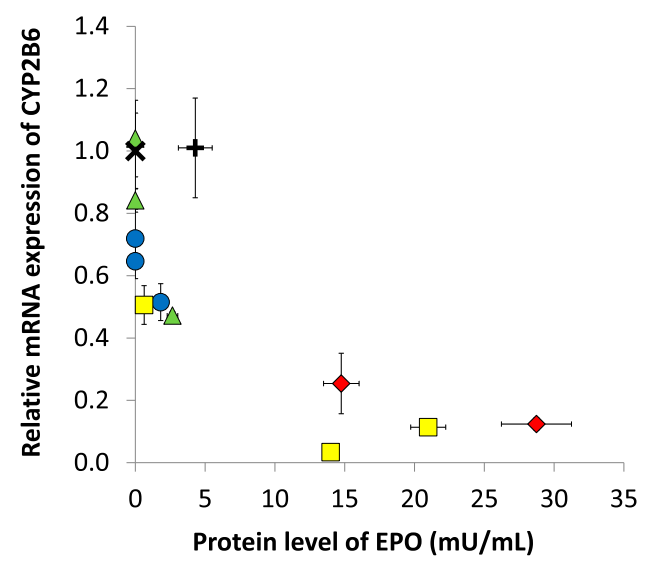

E CYP3A4 (strong PHD2 inhibitors)

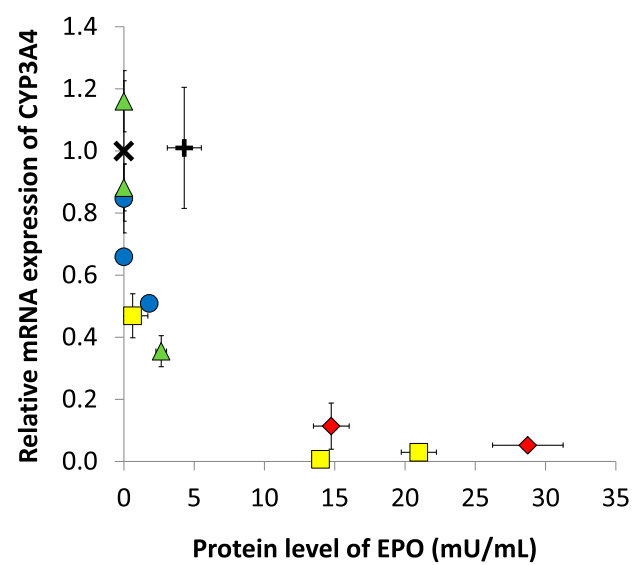

B CYP1A2 (weak PHD2 inhibitors)

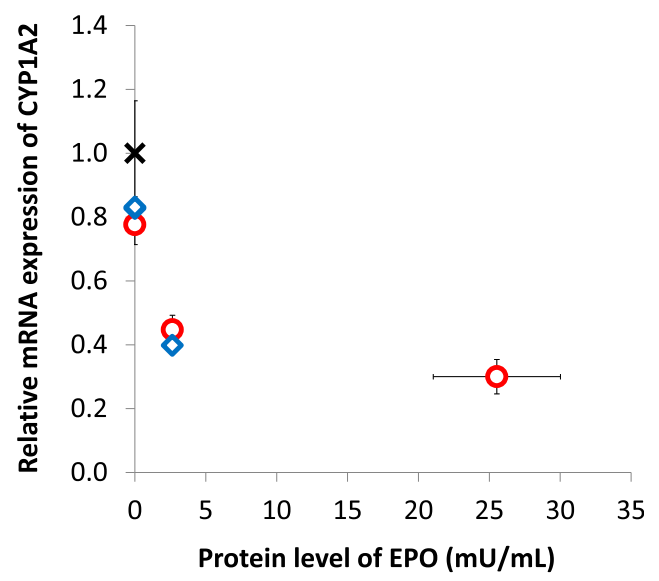

D CYP2B6 (weak PHD2 inhibitors)

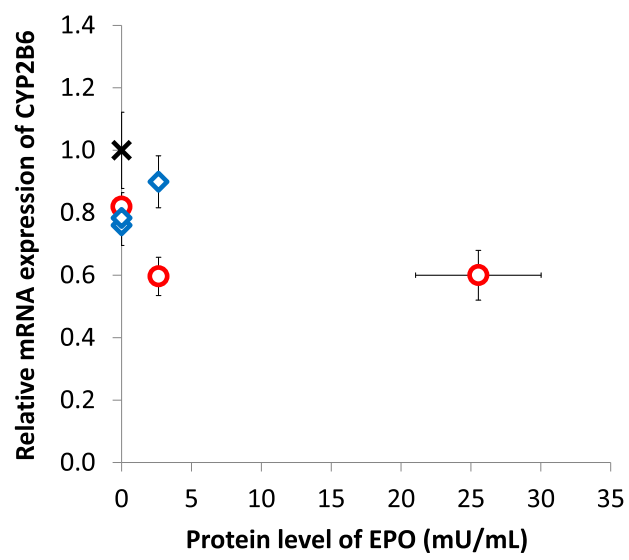

F CYP3A4 (weak PHD2 inhibitors)

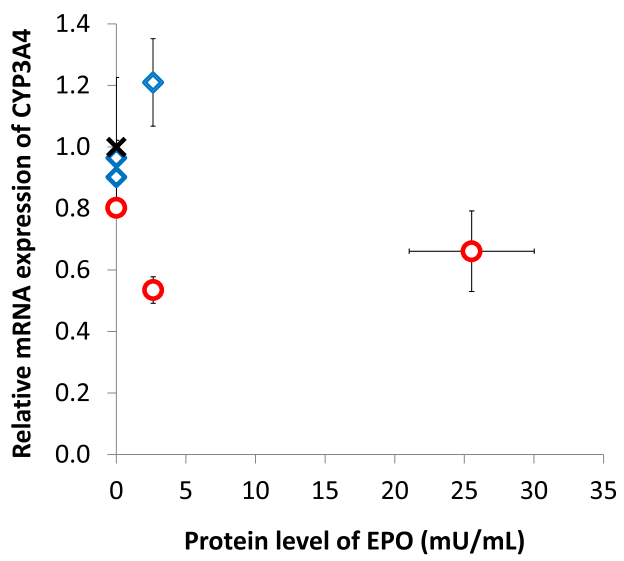

Fig. 4. Relationships of mRNA expressions of CYP1A2 (A and B), CYP2B6 (C and D), and CYP3A4 (E and F) with EPO production in human hepatocytes treated with the strong (A, C, and E) or weak (B, D, and F) PHD2 inhibitors. Compounds 1, 2, 5, and 6 are the strong PHD2 inhibitors. Compounds 3 and 4 are the weak PHD2 inhibitors. Human hepatocytes were incubated with the PHD2 inhibitors or a vehicle control, which were replaced daily for 72 hours. The concentrations tested were as follows: 1 and $10 \mu \mathrm{M}$ (compound 1); 0.1, 1, and $10 \mu \mathrm{M}$ (compounds 2-5); and 0.3,3, and $30 \mu \mathrm{M}$ (compound 6). Data represent the mean \pm S.D. $(n=3$ ).

possible mechanism is that an increase in the binding of stabilized HIF- $\alpha$ with ARNT could decrease the binding of AhR with ARNT, leading to a reduction of the transcription of CYP1A2 gene (Chan et al., 1999). On the other hand, the mRNA expression of CAR, PXR, and RXR was repressed. The mRNA expressions of these transcription factors were closely correlated with those of CYP2B6 and CYP3A4. The repression of CAR was comparable to that of CYP2B6. Moreover, the combined repression of PXR and RXR seemed to be comparable to the repression of CYP3A4, although each repression of PXR and RXR was weaker than that of CYP3A4. These results suggest that the decrease in CYP2B6 and CYP3A4 


\section{A CYP1A2-AhR}

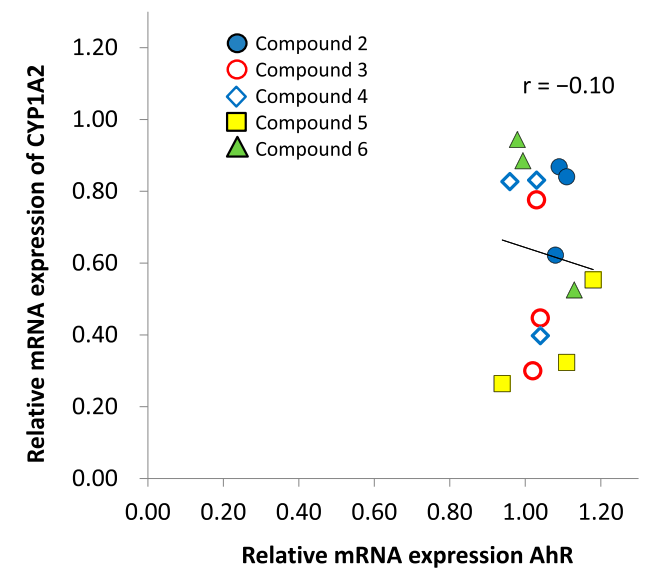

C CYP2B6-CAR

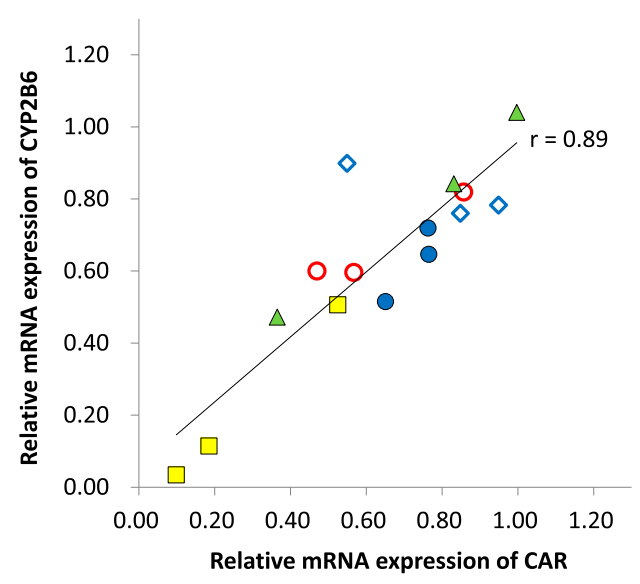

\section{E CYP3A4-PXR}

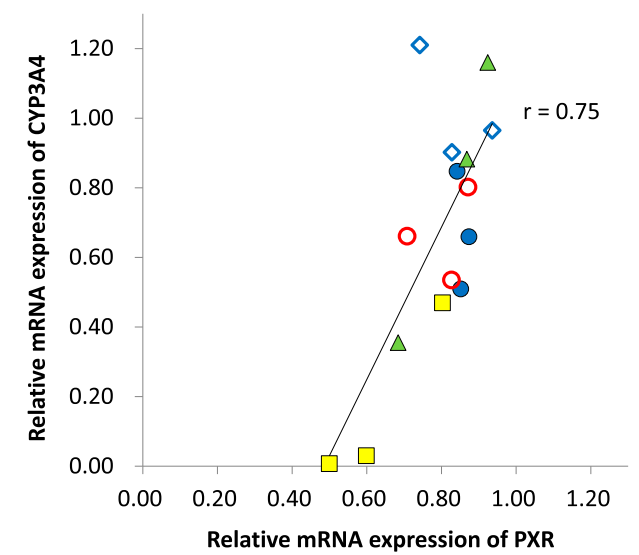

B CYP1A2-ARNT

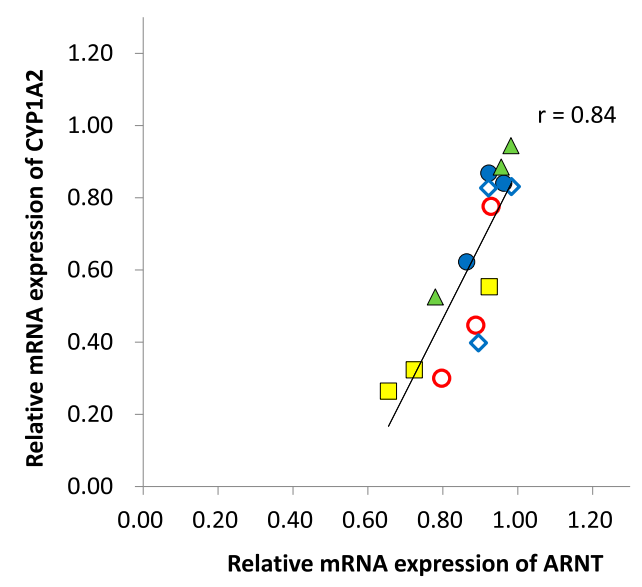

D CYP2B6-RXR
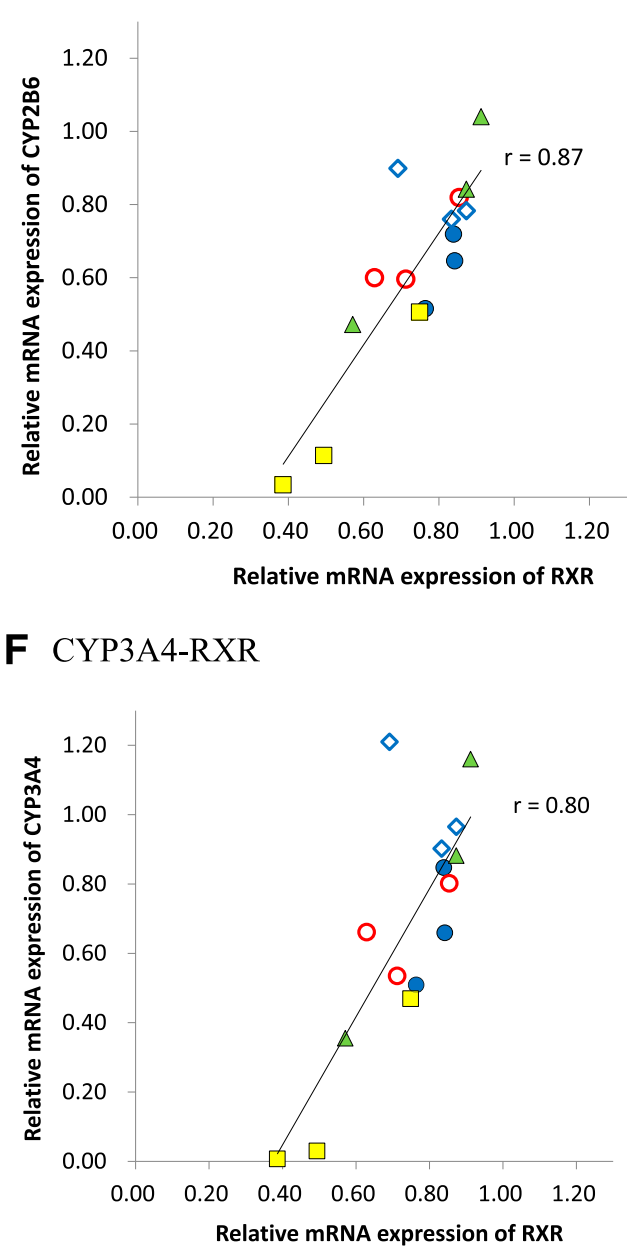

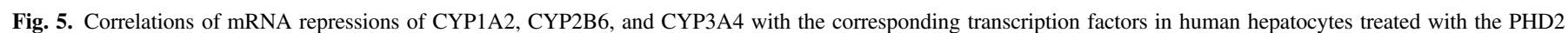

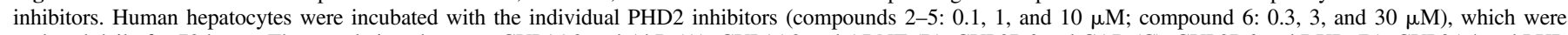

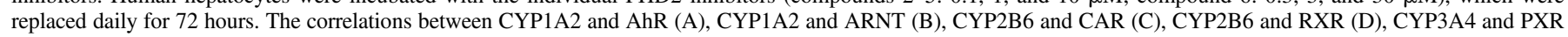

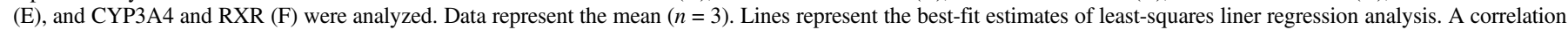
coefficient (r) is shown for each plot.

mRNA expression is probably caused by the repression of CAR, PXR, and RXR via an HIF- $\alpha$-dependent mechanism, although the mechanism for the downregulation of the transcription factors remains unknown.
A previous study conducted with HepaRG cells under hypoxia conditions $\left(1 \% \mathrm{O}_{2}\right.$ for 24 hours) showed that severe hypoxia downregulates the mRNA expressions of CYP1A2, CYP2C9, CYP3A4, 
CYP2E1, AhR, CAR, and PXR (Legendre et al., 2009). HepaRG is a highly differentiated cell line that displays many specific hepatocyte-like functions, including the activities of drug-metabolizing enzymes and transporters. Several studies have shown that HepaRG as well as human hepatocytes are valuable models for predicting the in vivo induction of CYP isoforms by drugs (Kanebratt and Andersson, 2008; Vermet et al., 2016), suggesting that HepaRG has the same functions that regulate CYP enzymes via transcription factors as human hepatocytes. Our observations of a decrease in mRNA levels of CYP enzymes and transcription factors in human hepatocytes are very similar with previous observations (Legendre et al., 2009) in HepaRG except for the results for AhR. AhR expression was repressed by hypoxia in the previous study (Legendre et al., 2009) but not by PHD2 inhibitors in the present study, indicating that the hypoxiainduced decrease in AhR expression in HepaRG appears to be independent of HIF- $\alpha$ stabilization. Other factors that are not implicated in HIF- $\alpha$ stabilization but occur secondary to hypoxia might be involved in the repression of AhR. On the other hand, HIF- $1 \alpha$ stabilization in HepaRG treated with desferrioxamine downregulates CYP3A4 expression without the direct binding of HIF- $1 \alpha$ to a putative hypoxia response elements site that is present in the $5^{\prime}$-flanking region of $C Y P 3 A 4$ gene and has no effect on the luciferase activity of the $C Y P 3 A 45^{\prime}$-flanking fragment $(-1100 /+11)$ (Legendre et al., 2009). The previous results do not conflict with our hypothesis that the downregulation of PXR and RXR is involved in the repression of CYP3A4 since PXR response elements are located in the $\sim 8$ $\mathrm{kb}$ upstream of the transcription initiation site as well as a proximal promoter region (Goodwin et al., 1999).

Several other mechanisms have been reported to be involved in the regulation of the expressions of CYP enzymes by hypoxia. Hypoxia induces nuclear factor $-\kappa \mathrm{B}(\mathrm{NF}-\kappa \mathrm{B})$ activity in HeLa cells (Oliver et al., 2009) and promotes the release of cytokines, including IL-2, IL-4, IL-6, and interferon $\gamma$, in phytohemagglutinin-stimulated human peripheral mononuclear cells (Naldini et al., 1997). All these factors would also contribute to the repression of CYP during hypoxia. Indeed, acute moderate hypoxia in rabbits downregulates CYP1A1, CYP1A2, CYP2B4, CYP2C5, and CYP2C16 by increasing cytokines, such as interferon $\gamma$, IL- $1 \beta$, and IL-2 (Fradette et al., 2007). In addition, the decrease in drug clearance associated with hypoxia in clinical is usually relevant to inflammation secondary to chronic obstructive lung disease, pneumonia, or acute bronchitis. Inflammation also produces cytokines, which lead to the downregulation of the CYP genes (Renton, 2004). Therefore, the clinical repercussions of HIF- $\alpha$ stabilization itself on CYP activity are difficult to evaluate separately from inflammation. In contrast, using PHD2 inhibitors in vitro could enable the contribution of HIF- $\alpha$ stabilization to CYP downregulation to be evaluated separately from other factors, such as NF- $\kappa \mathrm{B}$ and cytokines produced by hypoxia or inflammation. Our results suggest that clinical HIF- $\alpha$ stabilization itself may reduce CYP1A2, CYP2B6, and CYP3A4 activities without the involvement of NF- $\kappa \mathrm{B}$ or cytokines, thereby partially contributing to the decrease in drug clearance in patients with acute hypoxemia.

In conclusion, this is the first report to show that HIF- $\alpha$ stabilization downregulates CYP1A2, CYP2B6, and CYP3A4 using PHD2 inhibitors, which act as specific HIF- $\alpha$ stabilizers, as a new tool to mimic hypoxia in human hepatocytes. Although the underlying mechanism of the downregulation for CYP1A2 remains unclear, our results suggest that the decreases in the expressions of CAR, PXR, and RXR lead to the downregulation of CYP2B6 and CYP3A4 expressions via HIF- $\alpha$ stabilization. Our findings would contribute to a better understanding of the hypoxia-triggered regulatory mechanism of drug-metabolizing enzymes in human hepatocytes. Additional studies are required to fully understand the mechanism underlying the downregulation of transcription factors via HIF- $\alpha$ stabilization. Furthermore, the effects of the downregulation of transcription factors on drug transporters or phase
2 drug-metabolizing enzymes need to be evaluated to define the mechanism by which hypoxia affects drug clearance in greater detail.

\section{Acknowledgments}

We thank Takeshi Tani for useful discussions of the work described here. We also thank Yoshiki Fukazawa for valuable suggestions on the manuscript.

\section{Authorship Contributions}

Participated in research design: Takano, Yamaguchi.

Conducted experiments: Takano, Kato, Tada.

Contributed new reagents or analytic tools: Hamada.

Performed data analysis: Takano, Kato, Tada.

Wrote or contributed to the writing of the manuscript: Takano, Yamaguchi, Kato, Hamada, Tada, Endo.

\section{References}

Chan WK, Yao G, Gu YZ, and Bradfield CA (1999) Cross-talk between the aryl hydrocarbon receptor and hypoxia inducible factor signaling pathways. Demonstration of competition and compensation. J Biol Chem 274:12115-12123.

Cumming JF (1976) The effect of arterial oxygen tension on antipyrine half-time in plasma. Clin Pharmacol Ther 19:498-571.

du Souich P and Fradette C (2011) The effect and clinical consequences of hypoxia on cytochrome P450, membrane carrier proteins activity and expression. Expert Opin Drug Metab Toxicol 7 : $1083-1100$

Engel G, Hofmann U, Heidemann H, Cosme J, and Eichelbaum M (1996) Antipyrine as a probe for human oxidative drug metabolism: identification of the cytochrome P450 enzymes catalyzing 4 hydroxyantipyrine, 3-hydroxymethylantipyrine, and norantipyrine formation. Clin Pharmacol Ther 59:613-623.

European Medicines Agency (EMA) (2012) Guideline on the Investigation of Drug Interactions. Committee for Human Medicinal Products, London.

Food and Drug Administration (FDA) (2020) In Vitro Drug Interaction Studies - Cytochrome P450 Enzyme- and Transporter-Mediated Drug Interactions, Center for Drug Evaluation and Research, Silver Spring, MD.

Fradette C, Batonga J, Teng S, Piquette-Miller M, and du Souich P (2007) Animal models of acute moderate hypoxia are associated with a down-regulation of CYP1A1, 1A2, 2B4, 2C5, and 2C16 and up-regulation of CYP3A6 and P-glycoprotein in liver. Drug Metab Dispos 35:765-771.

Fradette C and du Souich P (2003) Hypoxia-inducible factor-1 and activator protein-1 modulate the upregulation of CYP3A6 induced by hypoxia. Br J Pharmacol 140:1146-1154.

Fradette C and Du Souich P (2004) Effect of hypoxia on cytochrome P450 activity and expression. Curr Drug Metab 5:257-271.

Goodwin B, Hodgson E, and Liddle C (1999) The orphan human pregnane X receptor mediates the transcriptional activation of CYP3A4 by rifampicin through a distal enhancer module. Mol Pharmacol 56:1329-1339.

Ivan M, Kondo K, Yang H, Kim W, Valiando J, Ohh M, Salic A, Asara JM, Lane WS, and Kaelin WG Jr (2001) HIFalpha targeted for VHL-mediated destruction by proline hydroxylation: implications for $\mathrm{O} 2$ sensing. Science 292:464-468.

Jaakkola P, Mole DR, Tian YM, Wilson MI, Gielbert J, Gaskell SJ, von Kriegsheim A, Hebestreit HF, Mukherji M, Schofield CJ, et al. (2001) Targeting of HIF-alpha to the von Hippel-Lindau ubiquitylation complex by O2-regulated prolyl hydroxylation. Science 292:468-472.

Kanebratt KP and Andersson TB (2008) HepaRG cells as an in vitro model for evaluation of cytochrome P450 induction in humans. Drug Metab Dispos 36:137-145.

Laybourn C, Tønnesen P, Loft S, Sonne J, and Døssing M (1986) Pulmonary disease and antipyrine clearance. Clin Pharmacol Ther 40:415-419.

Legendre C, Hori T, Loyer P, Aninat C, Ishida S, Glaise D, Lucas-Clerc C, Boudjema K, GuguenGuillouzo C, Corlu A, et al. (2009) Drug-metabolising enzymes are down-regulated by hypoxia in differentiated human hepatoma HepaRG cells: HIF-1alpha involvement in CYP3A4 repression. Eur J Cancer 45:2882-2892.

Mole DR, Blancher C, Copley RR, Pollard PJ, Gleadle JM, Ragoussis J, and Ratcliffe PJ (2009) Genome-wide association of hypoxia-inducible factor (HIF)-1 alpha and HIF-2alpha DNA binding with expression profiling of hypoxia-inducible transcripts. J Biol Chem 284:16767-16775.

Naldini A, Carraro F, Silvestri S, and Bocci V (1997) Hypoxia affects cytokine production and proliferative responses by human peripheral mononuclear cells. J Cell Physiol 173:335-342.

Oliver KM, Garvey JF, Ng CT, Veale DJ, Fearon U, Cummins EP, and Taylor CT (2009) Hypoxia activates NF-kappaB-dependent gene expression through the canonical signaling pathway. Antioxid Redox Signal 11:2057-2064.

Pharmaceuticals and Medical Devices Agency (PMDA) (2018) Guideline on Drug Interaction for Drug Development and Appropriate Provision of Information, Pharmaceuticals and Medical Devices Agency, Tokyo, Japan.

Piafsky KM, Sitar DS, Rangno RE, and Ogilvie RI (1977) Theophylline kinetics in acute pulmonary edema. Clin Pharmacol Ther 21:310-316.

Powell JR, Vozeh S, Hopewell P, Costello J, Sheiner LB, and Riegelman S (1978) Theophylline disposition in acutely ill hospitalized patients. The effect of smoking, heart failure, severe airway obstruction, and pneumonia. Am Rev Respir Dis 118:229-238.

Rabinowitz MH (2013) Inhibition of hypoxia-inducible factor prolyl hydroxylase domain oxygen sensors: tricking the body into mounting orchestrated survival and repair responses. J Med Chem 56:9369-9402.

Renton KW (2004) Cytochrome P450 regulation and drug biotransformation during inflammation and infection. Curr Drug Metab 5:235-243.

Rushmore TH and Kong AN (2002) Pharmacogenomics, regulation and signaling pathways of phase I and II drug metabolizing enzymes. Curr Drug Metab 3:481-490.

Sarkar MA, Hunt C, Guzelian PS, and Karnes HT (1992) Characterization of human liver cytochromes P-450 involved in theophylline metabolism. Drug Metab Dispos 20:31-37.

Semenza GL (2011) Oxygen sensing, homeostasis, and disease. N Engl J Med 365:537-547. 
Vermet H, Raoust N, Ngo R, Esserméant L, Klieber S, Fabre G, and Boulenc X (2016) Evaluation of normalization methods to predict CYP3A4 induction in six fully characterized cryopreserved human hepatocyte preparations and HepaRG cells. Drug Metab Dispos 44:50-60.

Wang GL and Semenza GL (1993) Desferrioxamine induces erythropoietin gene expression and hypoxia-inducible factor 1 DNA-binding activity: implications for models of hypoxia signal transduction. Blood 82:3610-3615.

Yuan Y, Hilliard G, Ferguson T, and Millhorn DE (2003) Cobalt inhibits the interaction between hypoxia-inducible factor-alpha and von Hippel-Lindau protein by direct binding to hypoxiainducible factor-alpha. J Biol Chem 278:15911-15916.
Zhang ZY and Kaminsky LS (1995) Characterization of human cytochromes P450 involved in theophylline 8-hydroxylation. Biochem Pharmacol 50:205-211.

Address correspondence to: Hiroki Takano, Drug Safety and Pharmacokinetics Laboratories, Taisho Pharmaceutical Co., Ltd., 1-403, Yoshino-cho, Kita-ku, Saitama 331-9530, Japan. E-mail: hir-takano@taisho.co.jp 